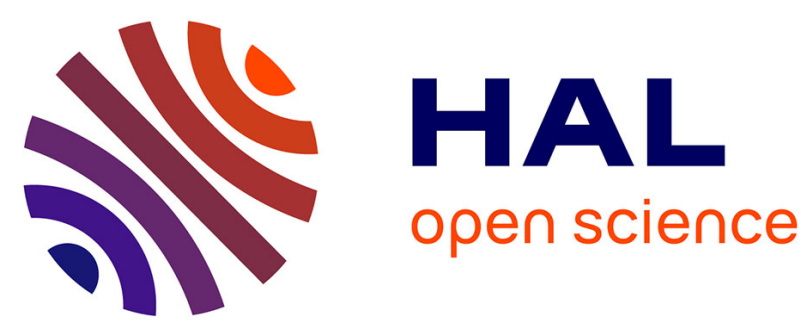

\title{
Rheological properties of molten flax- and Tencel@-polypropylene composites: Influence of fiber morphology and concentration
}

\author{
Ahmed Abdennadher, Michel Vincent, Tatiana Budtova
}

\section{- To cite this version:}

Ahmed Abdennadher, Michel Vincent, Tatiana Budtova. Rheological properties of molten flax- and Tencel®-polypropylene composites: Influence of fiber morphology and concentration. Journal of Rheology, 2016, 60 (1), pp.191-201. 10.1122/1.4938224 . hal-01263799

\section{HAL Id: hal-01263799}

https://hal-mines-paristech.archives-ouvertes.fr/hal-01263799

Submitted on 28 Jan 2016

HAL is a multi-disciplinary open access archive for the deposit and dissemination of scientific research documents, whether they are published or not. The documents may come from teaching and research institutions in France or abroad, or from public or private research centers.
L'archive ouverte pluridisciplinaire HAL, est destinée au dépôt et à la diffusion de documents scientifiques de niveau recherche, publiés ou non, émanant des établissements d'enseignement et de recherche français ou étrangers, des laboratoires publics ou privés. 


\title{
Rheological properties of molten flax- and Tencel ${ }^{\circledR}$-polypropylene composites: Influence of fiber morphology and concentration
}

\author{
Ahmed Abdennadher, Michel Vincent, and Tatiana Budtova: CrossMark \\ CEMEF-Centre de Mise en Forme des Matériaux, Mines ParisTech, PSL Research University, \\ UMR CNRS 7635, CS 10207, 06904 Sophia Antipolis, France
}

(Received 29 June 2015; final revision received 29 November 2015; published 5 January 2016)

\begin{abstract}
The rheological properties of short fiber reinforced polypropylene were investigated. Flax and Tencel ${ }^{\circledR}$ are two cellulose based fibers used in this study. Flax fibers are extracted from the bast of plants. They are composed of thin elementary fibers and rigid thick bundles made of elementary fibers "glued" together. Tencel ${ }^{\circledR}$ is a man-made cellulosic fiber spun from cellulose solution, with a uniform diameter, thin, and flexible. First, fiber dimensions before and after compounding were analyzed. Both types of fibers were broken during compounding. Flax shows larger length and diameter than Tencel ${ }^{\circledR}$, but aspect ratio of flax is smaller. The reason is that after compounding flax remained in bundles. Dynamic viscosity, elastic and viscous moduli were studied as a function of fiber type, concentration (from 0 to $30 \mathrm{wt} \%$ ), and composite temperature (from 180 to $200{ }^{\circ} \mathrm{C}$ ). All Tencel ${ }^{\circledR}$-based composites showed higher apparent yield stress, viscosity, and moduli compared to flax-based composites at the same fiber concentrations. The results are analyzed in terms of the influence of fiber type, aspect ratio, and flexibility. The importance of considering fiber morphology is demonstrated as far as it controls fiber flexibility and fiber-fiber interactions. (C) 2016 The Society of Rheology. [http://dx.doi.org/10.1122/1.4938224]
\end{abstract}

\section{INTRODUCTION}

Natural fiber-reinforced thermoplastics represent today a great potential enabling competition with glass fiber reinforced polymers. For example, in 2010 , $13 \%$ of the 8.7 million tonnes of the global fiber reinforced plastic market was taken by natural fibers reinforced polymers [1]. The advantages of natural fibers over glass are threefold. Natural fibers come from renewable resources, they are cheap and $30 \%-40 \%$ lighter than glass fibers. Natural fiber-reinforced thermoplastics are processed in the molten state via conventional ways such as extrusion and injection or compression. The understanding of composite rheological properties is thus a prerequisite for controlling, predicting, and also modeling composite processing.

One of the earliest rheological studies of natural fiber based composites was performed by Basu et al. [2] who compared the capillary rheology of jute- and glass fiber-filled polypropylene (PP). Authors showed that in both systems the viscosity of composite increases with increasing the fiber content at low shear rates, as expected, and converges to practically the same value at high shear rates. The increase of all viscoelastic properties (dynamic moduli, first and second normal stress differences, extensional viscosity) of polymer composites with nonspherical fillers, including natural fibers, was demonstrated in the review by Barnes [3]. Dynamic rheology of PP reinforced with jute [4], wood flour [5], hemp [6] and flax $[7,8]$ showed that the complex viscosity increases with the increase in the fiber content at low shear rates, and to lesser extent at higher shear rates in the shear thinning

\footnotetext{
a) Author to whom correspondence should be addressed; electronic mail: Tatiana.Budtova@mines-paristech.fr

regime. For hemp-, flax-, and sisal-based composites, an apparent yield stress was observed at low shear rates and high fiber content [6-8]. The yield behavior was interpreted by the formation of an elastic networklike structure due to fiberfiber interactions. Such a rheological response is similar to that of glass fiber reinforced thermoplastic [9-11]. The influence of compatibilizer (type and concentration) on viscoelastic properties of flax/PP and wood flower/polyethylene composites was studied by Sojoudiasli et al. [8] and Hristov and Vlachopoulos [12], respectively.

In most rheological studies of natural fiber reinforced polymers, the approaches used are those developed for suspensions of rigid particles of various aspect ratios. For example, the apparent yield stress is correlated only with fiber aspect ratio and concentration. However, natural fibers have a structure and a composition which are far more complicated than those of synthetic or glass fibers. Most natural fibers (except cotton) are "composites" themselves organized in bundles made of several elementary fibers. Depending on the processing conditions, these bundles may separate into elementary fibers. The natural fiber-polymer composite is thus a "mixture" of stiff bundles widely dispersed in diameter and length, and flexible or semiflexible elementary fibers of various lengths [13-16]. Therefore, fibers have different flexibilities and mechanical properties. It was shown that fiber elastic modulus decreases with the increase of bundle diameter [17-19]. There is thus a distribution of diameter and elastic modulus for natural fibers, which is not the case for glass fibers.

To interpret the rheological properties of a suspension of flexible fibers, Switzer et al. [20] used the criterion of flexibility $F$ that couples the fiber Young's modulus and the fiber aspect ratio with the shear stress 


$$
F=\frac{64}{\pi}\left(\frac{L}{D}\right)^{4} \frac{\eta_{m} \dot{\gamma}}{E}
$$

where $L / D$ is the aspect ratio, $\eta_{m}$ is the matrix viscosity, $\dot{\gamma}$ is the shear rate, and $E$ is the fiber Young's modulus. When $F$ $\rightarrow \infty$, fibers are perfectly flexible threads; when $F \rightarrow 0$ fibers become rigid and retain their shape under flow. Keshtkar et al. [21] applied this criterion to study steadystate and dynamic rheology of model synthetic fibers dispersed in silicone oil. They showed that for the same aspect ratio, shear stress, and fiber concentration, higher viscosity was obtained for fibers with higher flexibility. This trend was more pronounced for concentrated suspensions. They concluded that with more flexible fibers a "stronger structure" is formed due to a larger number of fiber-fiber interactions. According to this statement, a higher apparent yield stress $\sigma_{y}$ is expected for suspensions with more flexible fibers, as proved by Kerekes et al. [22] and Bennington et al. [23] for pulp and synthetic fibers immersed in water-based liquids. They defined the yield stress appearing due to the presence of fiber network (friction between fibers, elastic response due to fiber bending, etc.) as follows:

$$
\sigma_{y}=a E^{c}\left(\frac{L}{D}\right)^{d} \phi^{b},
$$

where $a, b, c$, and $d$ are constants for a given fiber type and $\phi$ is the fiber volume fraction. Bennington et al. [23] derived a theory for evaluating the yield stress based on elastic fiber bending that induces frictional resistance at fiber contact points. They obtained Eq. (2) with theoretical exponents $b=3, c=1$, and $d=2, a$ being an adjustable value.

The aim of this work is to study the influence of fibers type, flax vs Tencel ${ }^{\circledR}$, fiber concentration, and flexibility on the rheological behavior of molten natural fiber thermoplastic composite. We used the approaches developed for classical suspensions described above and applied them on cellulosic fiber-based polymer composites. The morphology of the chosen fibers is very different, which is expected to influence composite viscoelastic properties. Flax is a natural fiber represented by a mixture of semirigid thin elementary fibers and thick rigid bundles in which elementary fibers are glued together. Flax is known to have one of the best mechanical properties over the family of lignocellulosic fibers [24]. Tencel ${ }^{\circledR}$ is man-made pure cellulose fiber, thin, flexible, and with a uniform diameter over all the fiber population. One of the advantages of Tencel ${ }^{\circledR}$ is to be composed only of cellulose. Therefore, it degrades under temperature much less than lignocellulosic fibers. To the best of our knowledge, there is no study demonstrating the influences of cellulosic fiber type, morphology, and flexibility on the rheological properties of composites, whereas this seems extremely important for understanding and predicting the composite behavior during processing.

First, fiber length and diameter distributions in the composite are determined. The goal here is to demonstrate the importance of considering both fiber length and diameter to assess the fiber flexibility when dealing with flax fibers.
Then, dynamic rheology results are presented for different fiber concentrations and composite temperatures. Finally, the influence of temperature and of fiber type and flexibility on viscoelastic properties is discussed.

\section{MATERIALS AND METHODS}

\section{A. Materials}

The PP used as composite matrix is PPH9020 from Total Petrochemical. It is a homopolymer with a melting temperature of $165^{\circ} \mathrm{C}$ and a melt-flow index of $25 \mathrm{~g} / 10 \mathrm{~min}\left(230^{\circ} \mathrm{C}\right.$, $2.16 \mathrm{~kg}$ ) as given by the manufacturer.

Two types of cellulosic fibers were used: flax and Tencel $^{\circledR}$. Flax fibers were supplied by Dehondt Technologies (France) as NATTEX roving, Drakkar variety, harvested in France in 2010. These rovings were retted, scotched, combed, and then cut to a length of $0.5 \mathrm{~mm}$ by Apply Carbon. The initial state of flax is shown in Fig. 1(a). The elastic modulus may vary from 30 to $110 \mathrm{GPa}$, as reported in Charlet et al. [15,16].

The second type was Tencel ${ }^{\circledR}$ fibers. These are man-made cellulose II fibers produced with Lyocell process, kindly provided by Lenzing AG (Austria). Tencel ${ }^{\circledR}$ fibers are made by wet-spinning of eucalyptus pulp that is dissolved in N-methylmorpholine-N-oxide monohydrate. They are individual flexible fibers with a diameter of 10-11 $\mu \mathrm{m}$ [Fig. 1(b)]. Fibers with the average length of around $400 \mu \mathrm{m}$, as given by the producer, were made from longer fibers by milling. The elastic modulus is $10-15 \mathrm{GPa}$ according to Lenzing.

Decalin (decahydronaphthalene) from Sigma-Aldrich was used to dissolve PP to enable the fiber size analysis.

\section{B. Composite compounding}

Composites with $5,10,20$, and 30 wt. \% of fibers were prepared in a twin screw extruder. Before compounding, fibers were dried at $105^{\circ} \mathrm{C}$ for $2 \mathrm{~h}$. To improve the adhesion between fibers and matrix, a compatibilizer, such as maleic anhydride grafted PP, is usually added to PP. However, adding compatibilizer strongly influences matrix and thus composite viscoelastic properties (see, for example [6-8, 12]). This may trigger problems to interpret results especially when different fiber concentrations are used. Two issues are possible. First, when the amount of compatibilizer is proportional to that of fibers, the viscosity of the matrix/compatibilizer blend decreases compared to the neat matrix. At low fiber concentrations it may even lead to composite viscosity lower than that of the neat PP. Second, when the amount of compatibilizer remains unchanged at different fiber concentrations, the wetting between the matrix and fibers becomes different. In addition, the adhesion depends on the degree of grafting (amount of maleic anhydride) and the length of the grafted chains. Considering all said above and that the fibers used are of very different morphologies (see Fig. 1), no compatibilizer was used in this work.

The extruder was a Clextral BC21 with a centerline distance of $21 \mathrm{~mm}$ and a screw length of $900 \mathrm{~mm}$. The global flow rate was $7 \mathrm{~kg} / \mathrm{h}$ and the screw speed was $200 \mathrm{rpm}$. The compounding temperature was set at $190^{\circ} \mathrm{C}$, but the maximum measured temperature at the die exit was $195^{\circ} \mathrm{C}$. The 

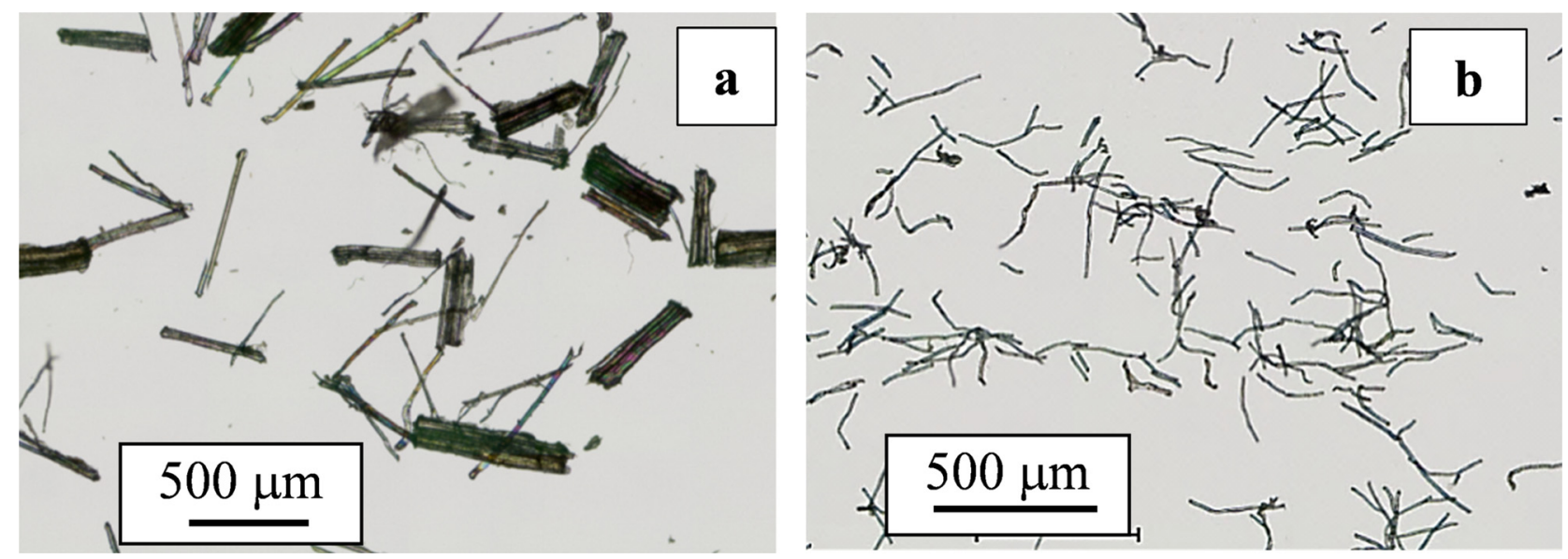

FIG. 1. Images of the fibers before processing taken with optical microscope: (a) flax fibers and (b) Tencel ${ }^{\circledR}$ fibers.

temperature rise is caused by the viscous heating. After compounding, the composite was granulated into pellets. Disks of $1.5 \mathrm{~mm}$ in thickness and $25 \mathrm{~mm}$ in diameter were made with a lab injection machine (Thermo Scientific HAAKE MiniJet II) for the rheological experiments. The injection temperature, mould temperature, injection, and holding pressures were $190^{\circ} \mathrm{C}, 50^{\circ} \mathrm{C}, 500$ bars, and 100 bars, respectively.

\section{Fiber size measurement}

Fiber length and diameter distributions after compounding were determined by dissolving the matrix (PP) in Decalin at $170{ }^{\circ} \mathrm{C}$ during $2 \mathrm{~h}$ under gentle stirring (see details in Le Moigne et al. [13] and Le Duc et al. [14]). It was previously demonstrated that Decalin is not affecting cellulosic fibers $[13,14,24-26]$. The amount of Decalin was such that the final fiber concentration in the mixture is less than $10 \mathrm{wt}$. $\%$ to avoid fiber overlapping and facilitate the size measurements. No filtration was used to avoid losing small fibers. A few drops of PP-decalin-fiber suspension were deposited on a glass plate. Stirring was performed before taking a droplet of suspension in order to avoid sedimentation of large fibers. The droplet was analyzed by using a Leica DP 4500 optical microscope in transmission mode equipped with a high resolution 3-CDD numerical camera (JVC KY-F75U, $1360 \times 1024$ pixels) and image analysis software (Cartograph and Archimed Microvision ${ }^{\circledR}$ software).

The fiber size analysis was performed on cartography built-up from 100 images per composite formulation. The measurement of fiber size was done semiautomatically. After selecting the fiber pattern "by hand," a numerical calliper integrated in the image acquisition software enabled the measurement of each fiber length and diameter. The statistical analysis was based on 200 fibers per sample. Each formulation was analyzed at least three times giving an error range of $10 \%$ in fiber size. The smallest size that was taken into account is $10 \mu \mathrm{m}$.

\section{Dynamic rheology}

Rheological measurements were performed in dynamic mode (small amplitude oscillatory shear) on Anton Paar rheometer MCR 302, using parallel plate geometry with $25 \mathrm{~mm}$ as diameter and $1 \mathrm{~mm}$ as gap. The rheological measurements were performed for a frequency range from 100 to $0.1 \mathrm{rad} / \mathrm{s}$ and for three different temperatures 180, 190, and $200^{\circ} \mathrm{C}$. The lowest frequency was chosen such that the duration of experiment was less than $20 \mathrm{~min}$, which is within the thermal stability time of composites. The strain was fixed at $1 \%$ over all tests, ensuring that all composites were in the linear viscoelastic regime.

\section{RESULTS}

\section{A. Analysis of fiber dimensions and orientation in composites}

To interpret the rheological results obtained for the molten composites, fiber dimensions must be determined. It is known that lengths and diameters of natural fibers decrease during compounding $[8,13,14]$. For glass fiber-based composites, it was demonstrated that the fiber breakage after compounding is far larger as compared to after injection moulding [27-30]. In the present work, a lab-scale injection molding machine was used to prepare the disks for the rheological experiments. Several reasons can explain why the fiber breakage can be neglected in this machine compared to a conventional injection molding one: (i) melting is driven by a heat conduction system, which does not damage fibers compared to the screw-barrel system; (ii) the path from the reservoir to the mold is shorter; and (iii) the injection speed is lower and thus the viscous stresses too. In addition, the gate dimensions, $2 \mathrm{~mm}$ as length and $1.5 \mathrm{~mm}$ as diameter, are much larger than fiber size coming out from extruder after compounding. Thus, we suppose that a negligible fiber breakage occurred during the injection moulding step.

Fiber length $L$ and diameter $D$ were measured before and after compounding and for composites of each concentration. The statistical analysis was carried out to determine size distributions and average lengths and diameters weighted in number (subscript "n") and in weight (subscript "w"): $L_{n}$, $D_{n}$, and aspect ratio $(L / D)_{n}$ and $L_{w}, D_{w}$ and aspect ratio $(L / D)_{w}$. Both types of values are indicated because they show different weights among fiber sizes. 

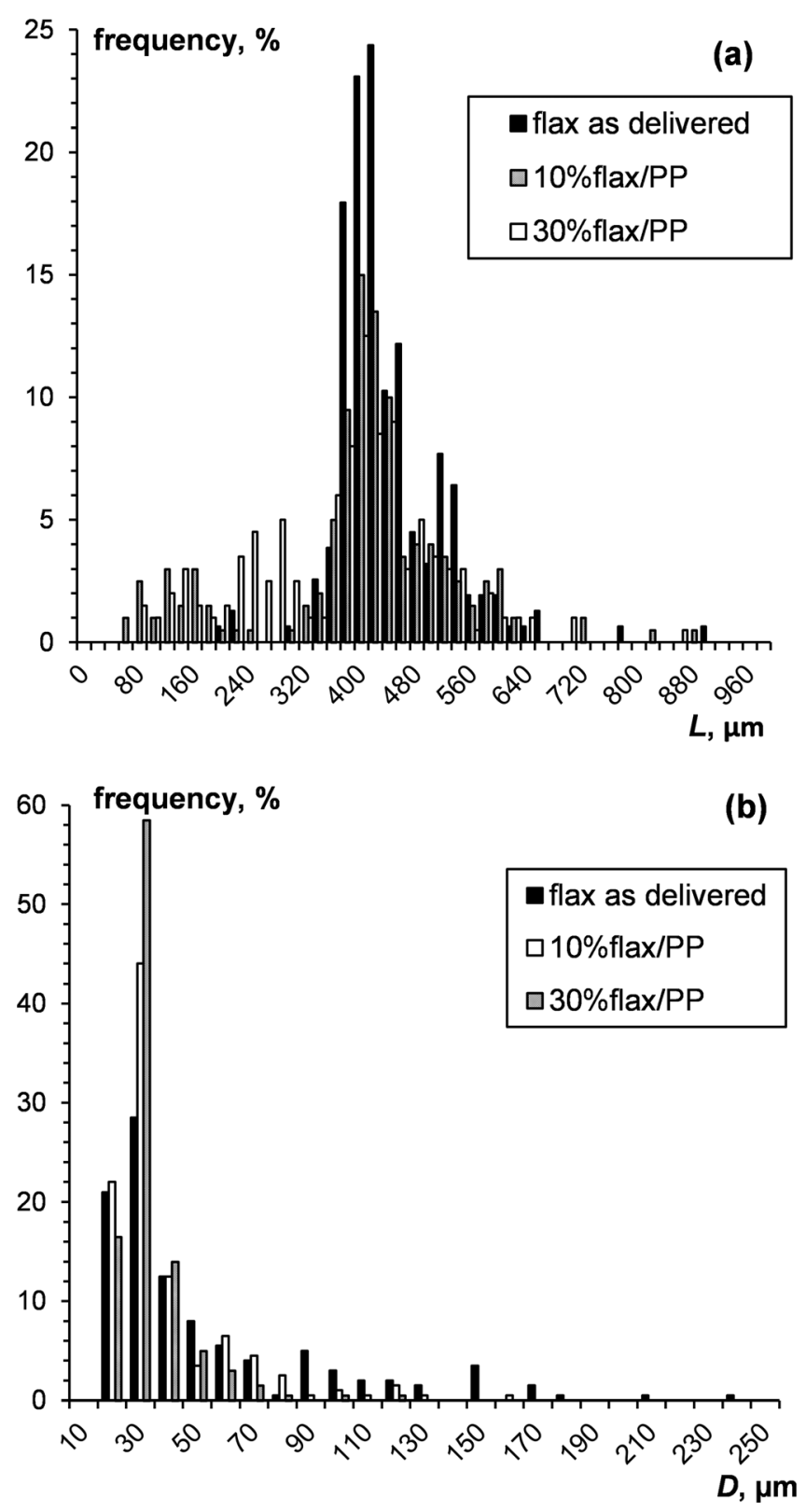

FIG. 2. Length (a) and diameter (b) distributions before and after compounding in 10 and $30 \mathrm{wt}$. \% flax/PP composite.
Figure 2(a) shows a comparison between the length distribution of flax fibers as delivered and after compounding for two composites with 10 and 30 wt. \% flax. All three distributions are similar but the amount of short fibers increases after compounding, indicating a fiber breakage. The increase of fiber concentration also leads to the decrease of fiber length, see Table I. Figure 2(b) compares the distribution of fiber diameter before and after compounding. The number of fibers with large diameter $(D>100 \mu \mathrm{m})$ decreased after compounding. This means that a part of the bundles was dissociated. The increase in fiber concentration also leads to a decrease in diameter, as depicted in Table I, from $48 \mu \mathrm{m}$ for the initial flax fibers to $28 \mu \mathrm{m}$ in the $30 \mathrm{wt}$. \% composite. Considering that the diameter of flax elementary fiber is around $10-15 \mu \mathrm{m}$, a large amount of flax fibers remained in bundles.

In the case of Tencel ${ }^{\circledR}$, the only variable is the length as the diameter remains constant. Few small particles may appear because of fibrillation, but this was not taken into account. Tencel ${ }^{\circledR}$ length distributions before compounding and for 10 and $30 \mathrm{wt}$. \% Tence ${ }^{\circledR} / \mathrm{PP}$ composites are given in Fig. 3. As for flax composites, the length of Tencel ${ }^{\circledR}$ decreases after compounding. The largest breakage occurs at $30 \mathrm{wt}$. \% by almost $30 \%$ as compared to the initial fibers.

Table I shows the evolution of $(L / D)_{n}$ and $(L / D)_{w}$ with fiber concentration for Tencel ${ }^{\circledR}$ and flax composites. For Tencel ${ }^{\circledR}$ fibers, the aspect ratio decreases when concentration increases from $(L / D)_{n}=30$ as delivered to $(L / D)_{n}=20$ at 30 wt. \%. For flax $(L / D)_{n}$ remains almost constant around 15 and $(L / D)_{w}$ slightly decreases from 20 as delivered to 17 at 30 wt. \%. For the compounding conditions used, length and diameter of flax fibers decrease keeping the aspect ratio practically unchanged. Despite their shorter length, Tencel ${ }^{\circledR}$ fibers exhibit a higher aspect ratio compared to flax. The reason is that some flax bundles are not dissociated during compounding even in highly concentrated composites.

The orientation of fibers was qualitatively studied by observing two cross-sections parallel to the disk circumference at $100 \mu \mathrm{m}$ depth (close to sample surface) and $750 \mu \mathrm{m}$ depth (midplane). The cross sections were obtained by polishing and imaged by optical microscopy in reflection. The main trend is that both Tencel ${ }^{\circledR}$ and flax are oriented parallel to the main disk surface (see examples of images in the

TABLE I. Number and weight average length, diameter and aspect ratio for flax and Tencel ${ }^{\circledR}$ fibers. Fiber concentration is shown as weight and volume fraction considering flax and Tencel ${ }^{\circledR}$ density being $1.5 \mathrm{~g} / \mathrm{cm}^{3}$.

\begin{tabular}{|c|c|c|c|c|c|c|c|}
\hline \multirow[b]{2}{*}{ Fiber type } & \multirow[b]{2}{*}{$\mathrm{wt} / \mathrm{vol} . \%$ in composite } & \multicolumn{2}{|c|}{ Length, $L(\mu \mathrm{m})$} & \multicolumn{2}{|c|}{ Diameter, $D(\mu \mathrm{m})$} & \multicolumn{2}{|c|}{ Aspect ratio, $L / D$} \\
\hline & & $L_{n}$ & $L_{w}$ & $D_{n}$ & $D_{w}$ & $(L / D)_{n}$ & $(L / D)_{w}$ \\
\hline \multirow[t]{5}{*}{ Flax } & Before compounding & 450 & 458 & 48 & 84 & 15 & 20 \\
\hline & $5 / 3.6$ & 433 & 478 & 35 & 46 & 15 & 18 \\
\hline & $10 / 6.3$ & 413 & 472 & 34 & 49 & 16 & 21 \\
\hline & $20 / 13.1$ & 434 & 469 & 39 & 60 & 15 & 18 \\
\hline & $30 / 20.5$ & 422 & 477 & 39 & 54 & 14 & 17 \\
\hline \multirow[t]{5}{*}{ Tencel $^{\circledR}$} & Before compounding & 300 & 338 & 10 & 10 & 30 & 34 \\
\hline & $5 / 3.6$ & 240 & 294 & 10 & 10 & 24 & 29 \\
\hline & $10 / 6.3$ & 242 & 318 & 10 & 10 & 24 & 32 \\
\hline & $20 / 13.1$ & 234 & 306 & 10 & 10 & 24 & 31 \\
\hline & $30 / 20.5$ & 195 & 264 & 10 & 10 & 20 & 26 \\
\hline
\end{tabular}




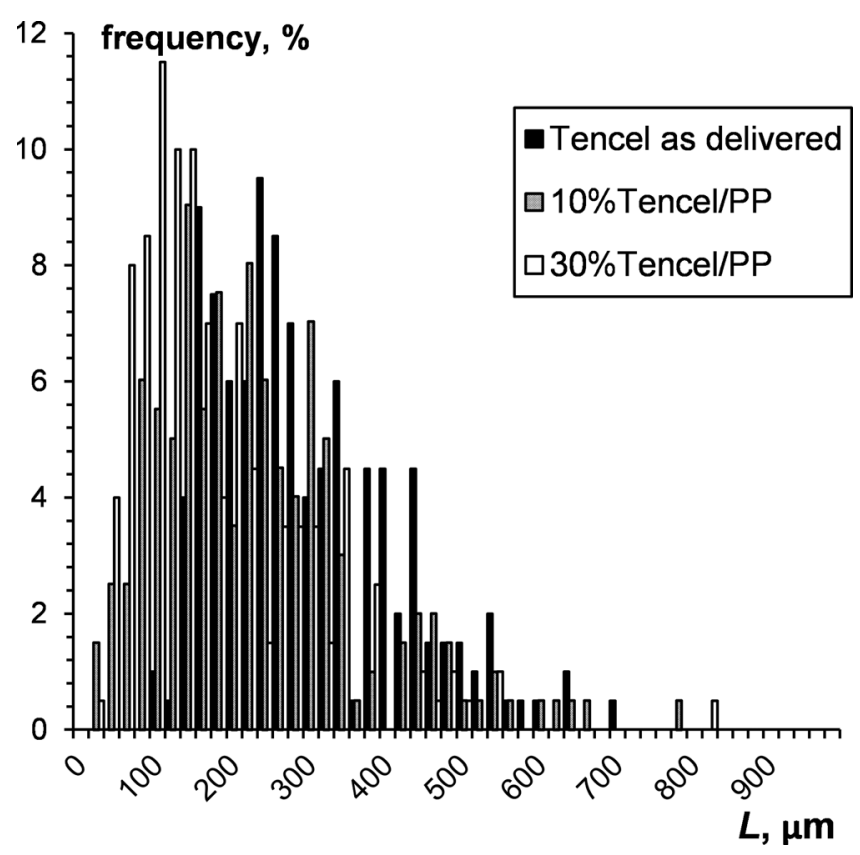

FIG. 3. Tencel ${ }^{\circledR}$ length distribution before and after compounding in 10 and 30 wt. \% Tencel $^{\circledR} / \mathrm{PP}$ composite.

supplementary material, Fig. S1 [31]). At a given cross section, fibers are randomly oriented at the middle of the disk, and aligned along the disk edge. The quantification of the fiber orientation in the disk is a complicated topic which must be separately investigated. Flax and Tencel fibers can be curved, which disables the use of approaches developed for characterizing the orientation of rigid fibers in injection moulded parts.

\section{B. Dynamic rheology}

\section{Preliminary results: Influence of the gap size, preshear and temperature}

The influence of the gap size on the rheological properties of composites was checked in the view of potential boundary effect. The viscosity of $20 \mathrm{wt}$. \% Tencel $^{\circledR} / \mathrm{PP}$ and $20 \mathrm{wt}$. \% flax/PP composites measured with the gaps of $0.75,1$, and $1.25 \mathrm{~mm}$ at $190^{\circ} \mathrm{C}$ is shown in Fig. S2 of the supplementary material [31]. No influence of the gap size was recorded within experimental errors. The reason is that fibers are oriented parallel to disk surfaces, and thus parallel to rheometer plates. Hence, it is the diameter and not the length that has to be considered when comparing fibers' size to the gap. The diameter of Tencel ${ }^{\circledR}$ fibers is $10-11 \mu \mathrm{m}$ and that of the thickest flax bundles is smaller than $200 \mu \mathrm{m}$, as shown in Fig. 2. Therefore, boundary effect can be excluded.

Reproducibility and the influence of preshear were studied. Figure S3 of the supplementary material [31] shows an example of viscosity vs frequency dependence for $20 \mathrm{wt}$. \% Tencel ${ }^{\circledR} / \mathrm{PP}$ composite at $190{ }^{\circ} \mathrm{C}$ for three independent measurements. The results are reproducible. Figure S4 of the supplementary material [31] shows an example of the influence of preshear on the viscosity of $20 \mathrm{wt}$. \% flax/PP and $20 \mathrm{wt}$. \% Tencel ${ }^{\circledR} / \mathrm{PP}$ composites, both at $190^{\circ} \mathrm{C}$. A slight viscosity decrease with the increase of preshear rate was recorded for flax-based composite, while practically no influence of preshear on Tencel ${ }^{\circledR} / \mathrm{PP}$ system was observed. A similar result for flax composites at low preshear was reported by Sojoudiasli et al. [8]. We did not preshear the composites in order to keep the initial fiber orientation in the injected disks for both types of fibers.

The thermal stability of composites was also checked. Whereas a slight decrease in $\mathrm{G}^{\prime \prime}$ after $1 \mathrm{~h}$ of shear is obtained at high fiber concentrations, it remains within 5\% deviation \{see Figs. S5(a)-S5(c) of the supplementary material [31]\}. Considering that the duration of the frequency sweep test is $20 \mathrm{~min}$, we can thus accept that no viscosity variation within the experimental errors was recorded.

\section{Influence of fiber concentration on composite viscoelastic properties}

Figures 4(a) and 4(b) show complex viscosity $\eta^{*}$ and tan $\delta=G^{\prime \prime} / G^{\prime}$ (where $G^{\prime}$ and $G^{\prime \prime}$ are elastic and viscous moduli,
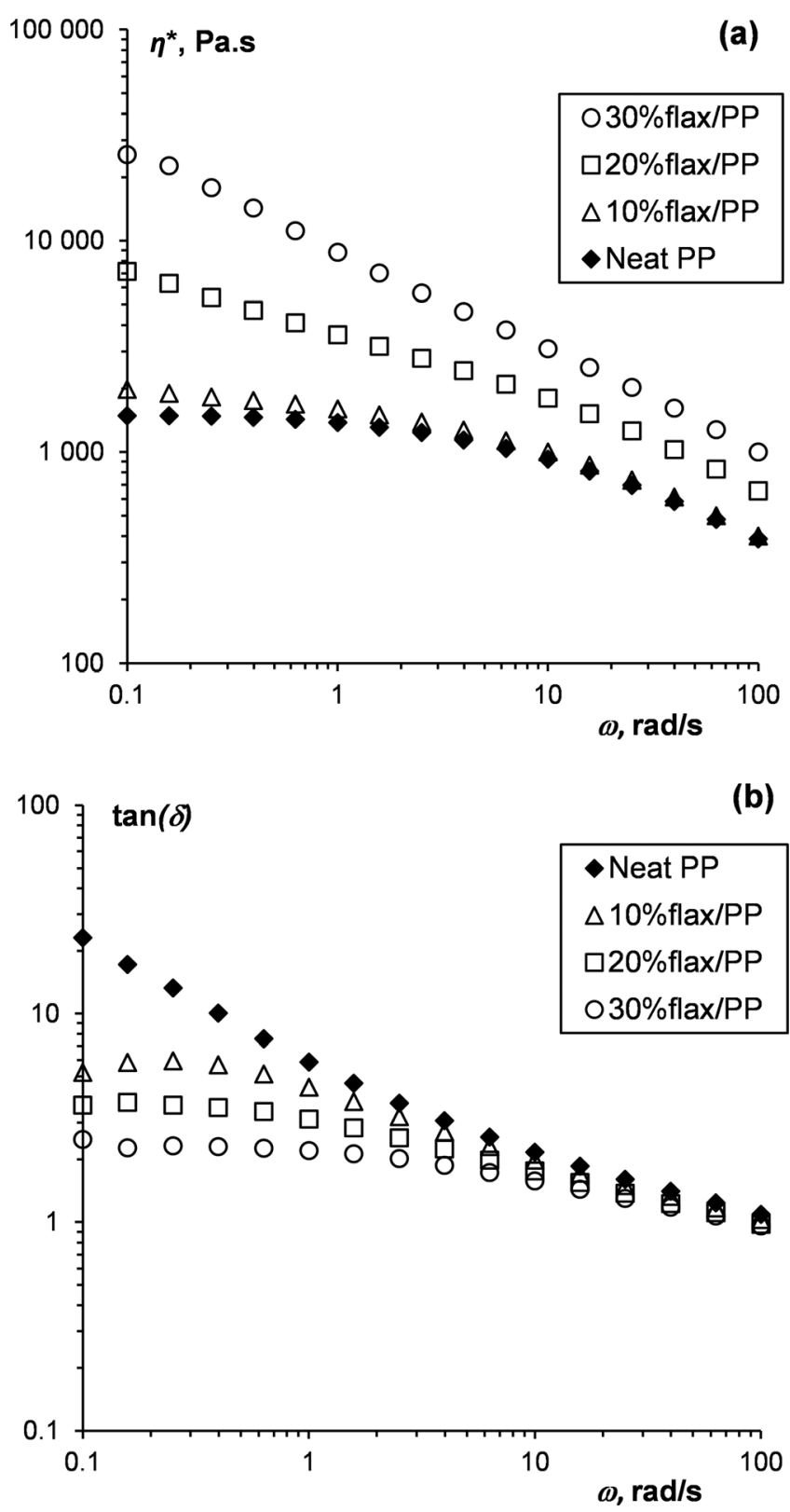

FIG. 4. Complex viscosity (a) and $\tan \delta$ (b) vs frequency at $190^{\circ} \mathrm{C}$ for the neat PP and flax/PP composites with 10,20, and 30 wt. \% flax. 
respectively) as a function of frequency $\omega$ at $190{ }^{\circ} \mathrm{C}$ for the neat PP and composites with 10, 20, and $30 \mathrm{wt}$. \% of flax. Similar results were obtained for Tencel ${ }^{\circledR}$-based composites (not shown). Neat PP shows a classical rheological behavior with a Newtonian plateau at low frequencies and shear thinning at higher frequencies. The viscosity gets greater and the Newtonian plateau disappears as the fiber content increases.

The tangent of phase angle $\delta$ represents to what extent the system is more viscous or more elastic. Over all studied systems $\tan \delta$ is greater than 1 throughout the whole range of studied frequencies [Fig. 4(b)]. The lower the frequency is, the higher the $\tan \delta$ is. An increase in fiber concentration leads to a decrease of $\tan \delta$, indicating an increase of system elasticity which is more pronounced at low frequencies. For 30 wt. $\%$ flax/PP composite, $\tan \delta$ is close to 2 at low frequencies and to 1 at high frequencies. For glass fiber
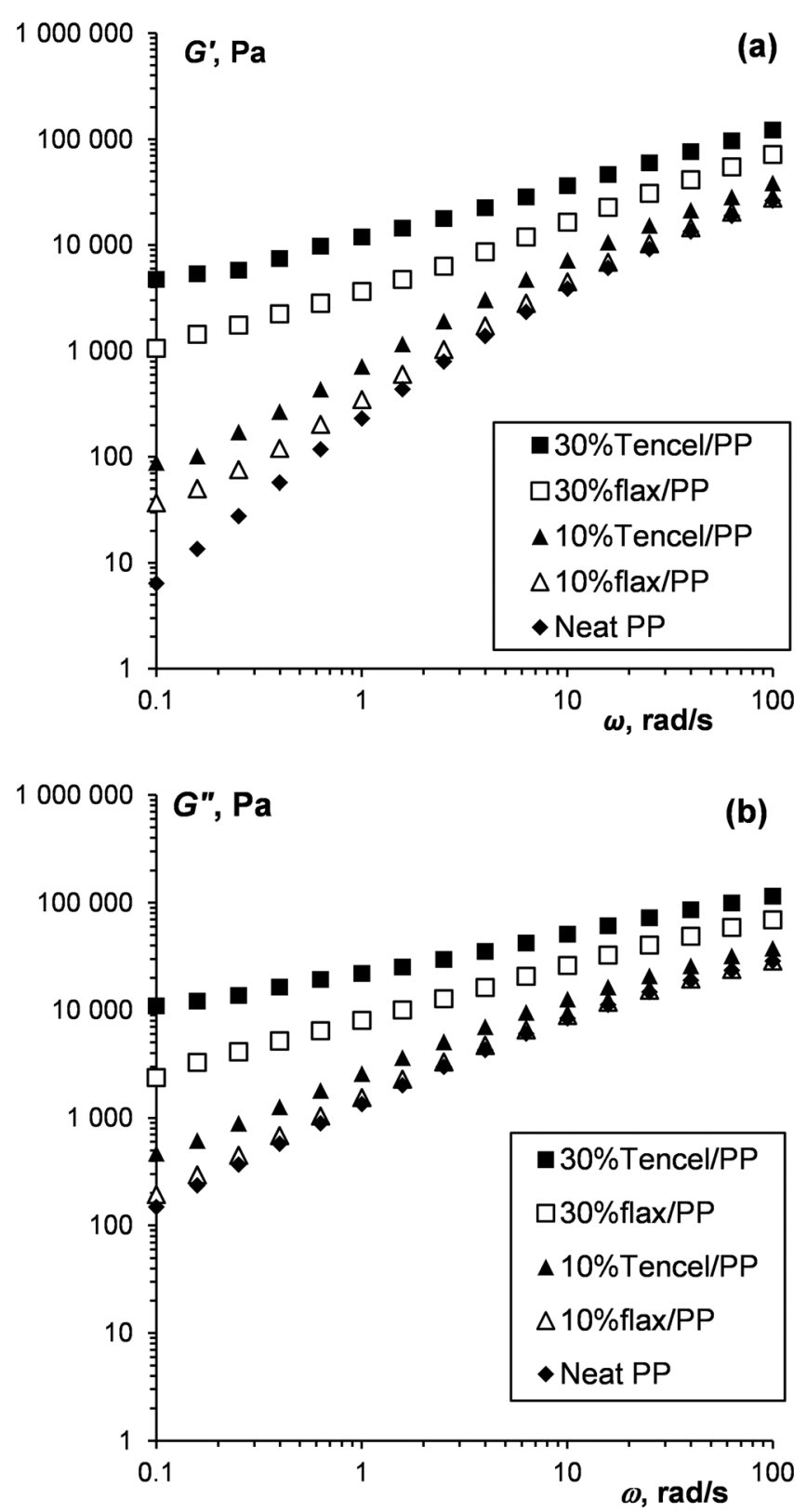

FIG. 5. Storage $\mathrm{G}^{\prime}$ (a) and loss $\left(\mathrm{G}^{\prime \prime}\right)$ (b) moduli vs frequency at $190^{\circ} \mathrm{C}$ for the neat PP and $10 \mathrm{wt} . \%$ and $30 \mathrm{wt} . \%$ Tencel $^{\circledR} / \mathrm{PP}$ and flax/PP composites. reinforced thermoplastics, $G^{\prime \prime} / G^{\prime}$ is usually found to be higher than 1, independent of glass fiber content and equal to that of the matrix [32,33]. For glass fiber reinforced PP, it was also reported that $G^{\prime \prime} / G^{\prime}>1[34,35]$; at low frequencies $\tan \delta$ decreased with fiber content, and at high frequencies it remained constant. For 50 wt. \% flax reinforced highly concentrated PP Le Moigne et al. [7] found that $\tan \delta<1$.

Figures 5(a) and 5(b) show $G^{\prime}$ and $G^{\prime \prime}$ of neat PP and of composites with 10 and $30 \mathrm{wt}$. $\%$ of Tencel ${ }^{\circledR}$ and flax. The higher the fiber concentration is, the higher both moduli are. This effect is more pronounced at low frequencies and especially for Tencel ${ }^{\circledR}$-based composites. According to Maxwell model of viscoelastic fluids, $G^{\prime} \sim \omega^{x}$ and $G^{\prime \prime} \sim \omega^{y}$ with $x=2$ and $y=1$ at low frequencies. For the neat PP, $x=1.6$ and $y=0.98$. The deviation of $x$ exponent from the model value may be due either to the polydispersity of the polymer or simply to the limitation of the low frequency range. Both exponents decrease when fiber concentration increases. This trend is more pronounced for Tencel ${ }^{\circledR}$-based composites. For example, for $10 \mathrm{wt}$. $\%$ composites $x=0.86$ and $y=0.92$ for flax/PP and $x=0.84$ and $y=0.73$ for Tencel $^{\circledR} / \mathrm{PP}$ while for 30 wt. \% composites $x=0.53$ and $y=0.56$ for flax/PP and $x=0.32$ and $y=0.29$ for Tencel $^{\circledR} / \mathrm{PP}$. The low-frequency plateaulike $G^{\prime}$ and $G^{\prime \prime}$ for the concentrated Tencel ${ }^{\circledR}$-based composites is a sign of a solidlike behavior of the system. This phenomenon is correlated with the loss of the Newtonian plateau on the viscosity-frequency dependence (Fig. 4).

Figures 4 and 5 suggest that both types of concentrated composites are yield stress fluids. Two methods can be used for the determination of the apparent yield stress. The first one consists of extrapolating the shear stress vs shear rate (or frequency) to zero shear rate (or frequency) (see, for example [36,37]. The second consists of using a modified Herschel-Bulkley model and plotting the viscosity vs complex modulus or shear stress (see, for example [37,38]). The viscosity increases asymptotically as the shear stress decreases. The asymptotic value enables deducing the apparent yield stress. Both methods need an extrapolation at low shear stress or shear rate, which may lead to some differences among apparent yield stress values.

We tested these methods for the composites studied \{ see examples in Figs. 6(a) and 6(b) and also Fig. S6 of the supplementary material [31]\}. The extrapolation of the flow curve to zero frequency is always possible whatever the level of the yield stress. With the second method, the increase of viscosity is sharp for Tencel ${ }^{\circledR}$ composites for the two highest concentrations, but it is not well pronounced for flax fiber case (see Fig. S6 of the supplementary material [31]). It would be necessary to make measurements at lower frequencies, but this is not possible because of long measurement time leading to fiber thermal degradation.

Both methods lead to similar values of the apparent yield stress for Tencel ${ }^{\circledR}$ composites [Figs. 6(a) and 6(b)]. Therefore, we used the first method for investigating the influence of fiber type and concentration (here, volume fraction $\phi$ ) on the apparent yield stress for two temperatures, 180 and $200^{\circ} \mathrm{C}$ (Fig. 7). It should be noted that at fibers' concentration below $10 \mathrm{wt}$. \% (equivalent to $6 \mathrm{vol}$. \%) the apparent yield stress is very low, below $1 \mathrm{~Pa}$, and thus should 

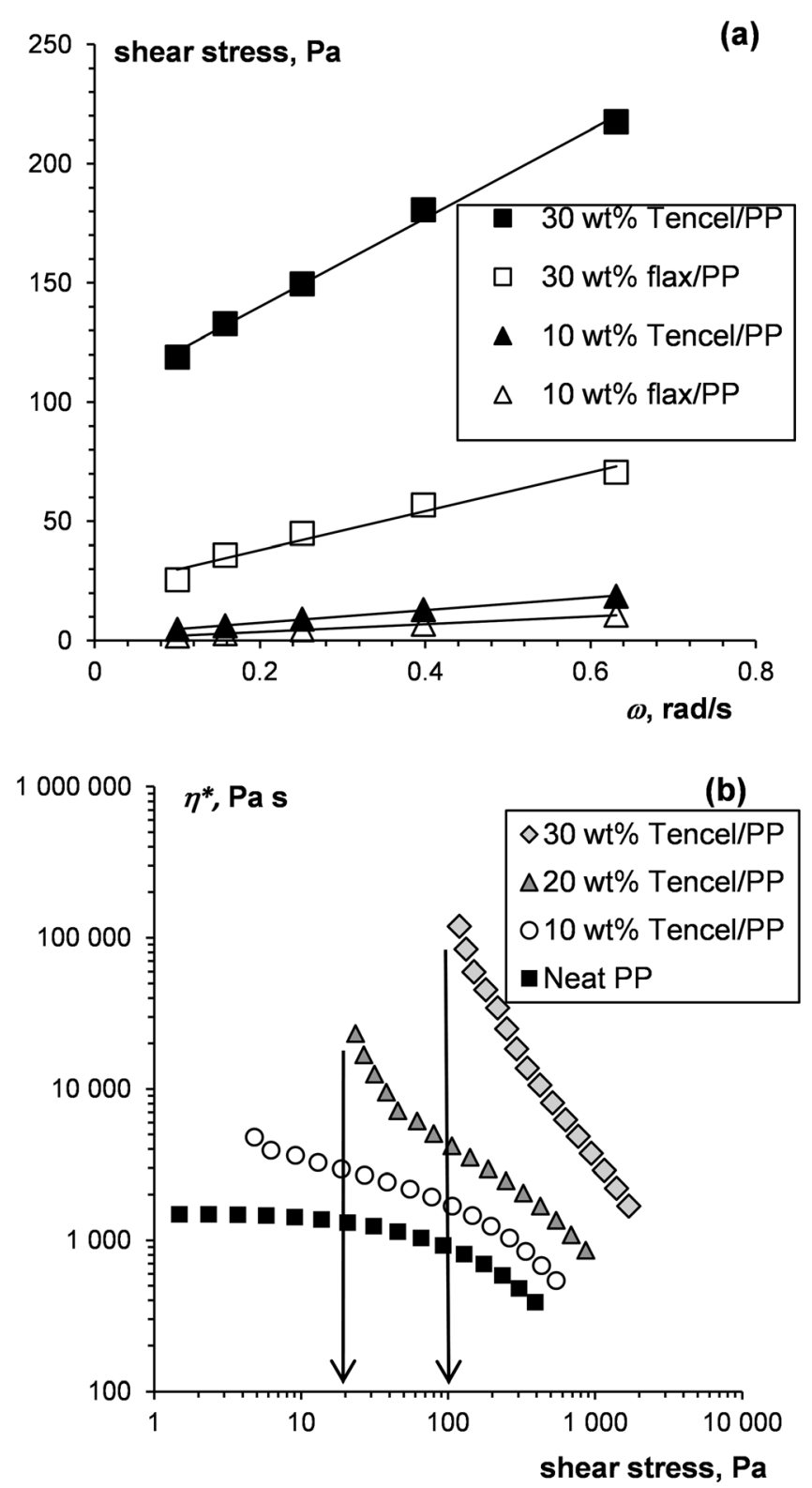

FIG. 6. Illustration of determination of apparent yield stress, example for $190^{\circ} \mathrm{C}$ : (a) extrapolation of shear stress vs frequency to zero frequency for 30 and 10 wt. \% Tencel ${ }^{\circledR} / \mathrm{PP}$ and flax/PP composites and (b) viscosity vs shear stress for the neat PP and 10,20, and $30 \mathrm{wt} . \%$ Tencel $^{\circledR} / \mathrm{PP}$, apparent yield stress is shown by arrows.

be considered with care. The apparent yield stress is significant for Tencel ${ }^{\circledR}$ fibers at concentration larger than $10 \mathrm{wt} . \%$, and for flax fibers at $30 \mathrm{wt} . \%$. The apparent yield stress increases with the concentration increase, and is higher for all Tencel ${ }^{\circledR}$-based composites (Fig. 7).

The apparent yield stress-concentration data were fitted with Eq. (2) (solid lines in Fig. 7). In both cases, the apparent yield stress is proportional to fiber volume fraction in the power 3 within $10 \%$ deviation, as predicted by Bennington et al. [23] [ $b=3$ in Eq. (2)]. It is difficult to predict the other exponents in Eq. (2) because there are too many variables and the influence of temperature on fiber Young's modulus is not known. Supposing that the apparent yield stress is proportional to $(L / D)_{n}$ (Table I) in power 2 as suggested by Bennington et al. [23] and taking the mean values of the

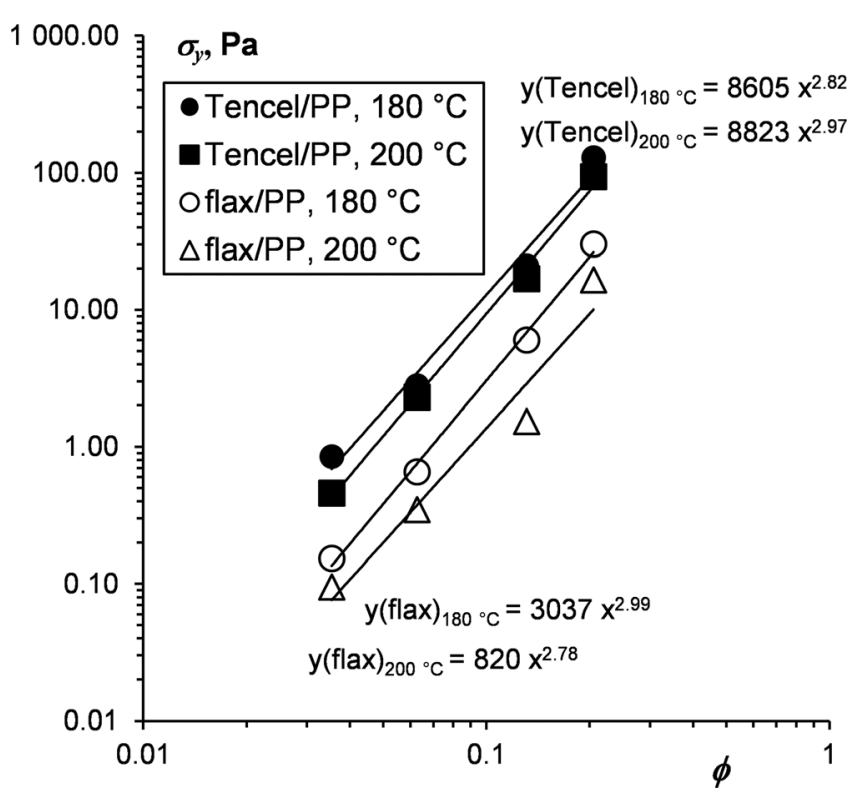

FIG. 7. Apparent yield stress evolution with fiber volume fraction for Tencel ${ }^{\circledR} / \mathrm{PP}$ (dark symbols) and flax/PP (open symbols) composites at 180 and $200^{\circ} \mathrm{C}$; lines are power law approximations according to Eq. (2).

elastic modulus for each type of fiber, $E_{\text {Tencel }}=13 \mathrm{GPa}$ and $E_{\text {flax }}=70 \mathrm{GPa}$ (see Sec. II), a rough estimation of the exponent $c$ for the dependence of the apparent yield stress on Young's modulus gives $0.88<c_{\text {Tencel }}<1.17$ for Tencel ${ }^{\circledR}$ based composites and $0.30<c_{\text {flax }}<0.61 . c_{\text {Tencel }}$ fits well the theoretical prediction $(c=1)$. For flax-based composites the reason of the deviation of the exponent from the theoretical value can be due to the huge fibers heterogeneity: the bundles with different number of elementary fibers induce a large variation in "fiber" elastic modulus (the modulus of an elementary fiber is higher than that of a bundle $[15,16])$. The composition of fibers, i.e., the ratio between cellulose, lignin,

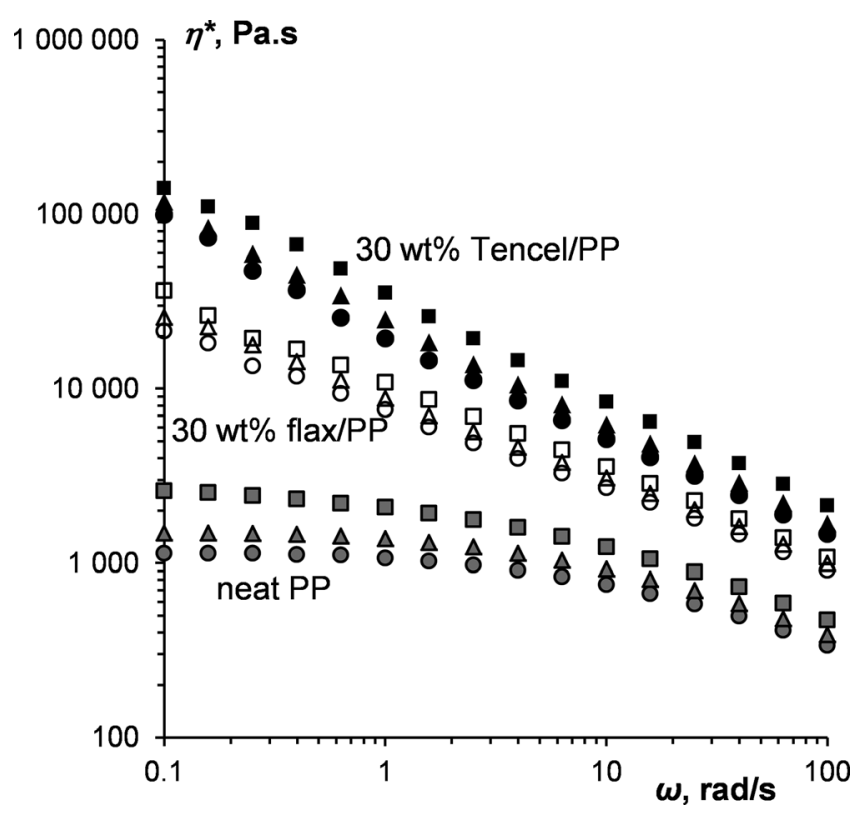

FIG. 8. Viscosity vs frequency for the neat PP, $30 \%$ flax/PP, and $30 \%$ Tencel ${ }^{\circledR} / \mathrm{PP}$ composite at three temperatures: 180 (squares), 190 (triangles), and $200^{\circ} \mathrm{C}$ (circles). 
pectin, hemicelluloses, and waxes, also varies from bundle to bundle, inducing a difference in their moduli.

\section{Viscosity-temperature dependence}

It is known that the viscosity of classical polymer melts decreases when temperature increases. Figure 8 shows an example of complex viscosity-frequency dependence for the case of the neat PP and $30 \mathrm{wt}$. \% flax and Tencel ${ }^{\circledR}$ composite at different temperatures $\left(180,190\right.$, and $\left.200^{\circ} \mathrm{C}\right)$. Similar results were obtained for other fiber concentrations. As expected, viscosity decreases when temperature increases for all studied systems. Master plots were built using timetemperature superposition principle, and shift factors $a_{T}$ for each composite were determined. Figure 9 shows examples for the neat PP, 30 wt. \% flax/PP and 30 wt. \% Tencel ${ }^{\circledR} / \mathrm{PP}$ composites. Similar time-temperature superposition fits was reported for glass/PP composites [39]. Temperature dependence of this factor is known to obey Eq. (3) enabling the calculation of the activation energy $E_{a}$

$$
a_{T}=\exp \left[\frac{E_{a}}{R}\left(\frac{1}{T}-\frac{1}{T_{0}}\right)\right]
$$

where $R$ is the universal gas constant, $T$ is the temperature in $\mathrm{K}$, and $T_{0}$ is the reference temperature (here $463 \mathrm{~K}$ ).

Figure 10 shows the activation energy for both Tencel ${ }^{\circledR}$ and flax based composites as a function of fiber concentration. $E_{a}$ increases with fiber content for both types of fibers being higher for composites with Tencel ${ }^{\circledR}$. The difference of activation energy between both fibers increases with the fiber concentration.

The activation energy of viscous flow is historically derived from thermodynamic considerations. Flow is seen as a local transition of a molecule or a group of molecules between one state (position before flowing) to another (position after flow occurred) having to overcome an energy

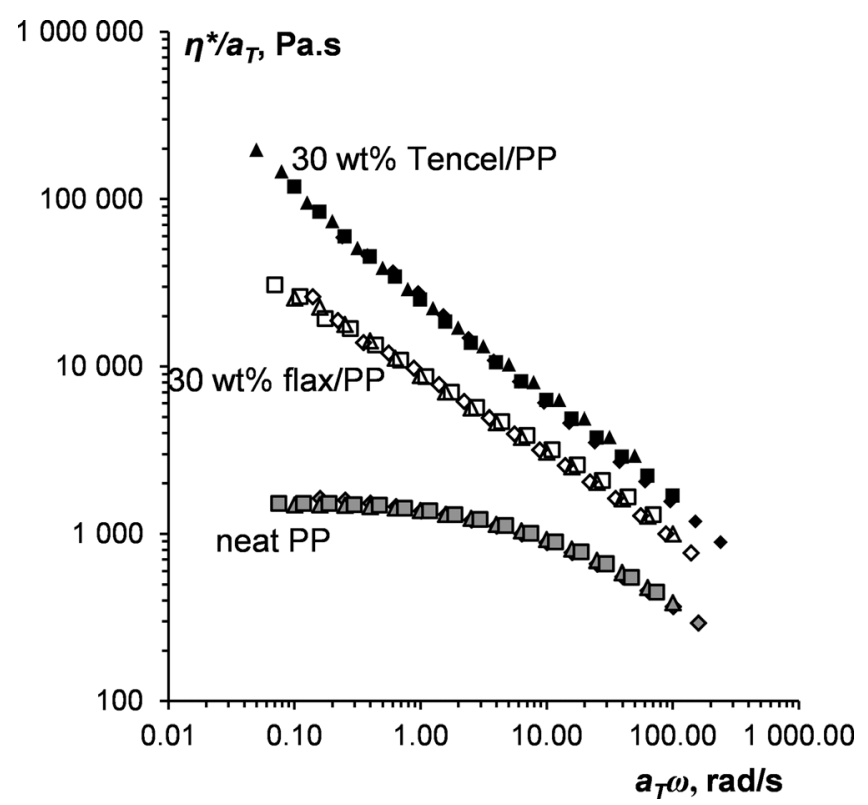

FIG. 9. Master plots of the neat PP, $30 \mathrm{wt} \%$ flax/PP, and $30 \mathrm{wt}$. \% Tencel $^{\circledR} /$ $\mathrm{PP}$ at the reference temperature $190^{\circ} \mathrm{C}$.

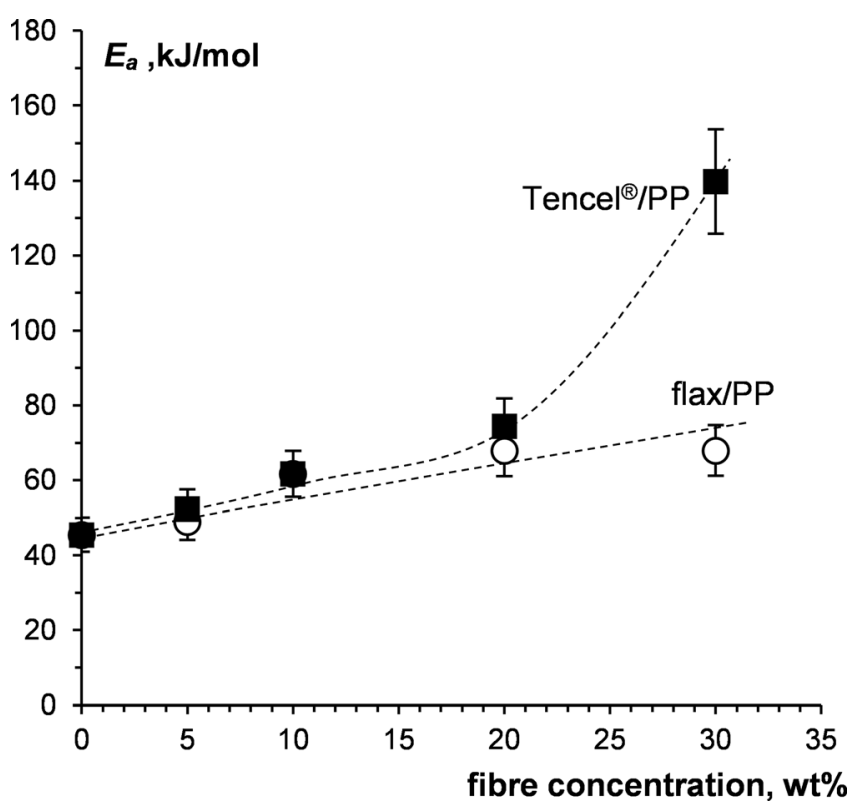

FIG. 10. Activation energy evolution with fiber concentration for Tencel ${ }^{\circledR} /$ $\mathrm{PP}$ and flax/PP composites; zero fiber content corresponds to the neat PP. The dashed lines are given to guide the eye.

barrier [40-43]. For polymer solutions, the activation energy thus inevitably increases as the polymer concentration gets larger. For polymer melts, the activation energy depends on the proximity to glass transition temperature, on polymer molecular weight to a certain extent, chain flexibility, type and amount of side chains, and on chain-chain interactions. For molten composites, two opposite trends for the activation energy dependence as a function of fiber content were reported in the literature. For coir/PP composite $E_{a}$ increases from about $40 \mathrm{~kJ} / \mathrm{mol}$ for the neat PP to about $80 \mathrm{~kJ} / \mathrm{mol}$ for $30 \mathrm{wt}$. \% coir/ PP system [44], which is interpreted by polymer melt "dragging" the inert fibers into fluid motion that needs a higher energy than when flowing without fibers. Conversely, for sisal fiber/poly(butylene succinate) composites $E_{a}$ decreased from $35 \mathrm{~kJ} / \mathrm{mol}$ for the neat polymer to $1-2 \mathrm{~kJ} / \mathrm{mol}$ for $50 \mathrm{wt}$. \% sisal composite [45] and for glass fibers/PP composites from $10 \mathrm{~kJ} /$ mol for the neat PP to $6 \mathrm{~kJ} / \mathrm{mol}$ for $30 \mathrm{wt}$. $\%$ glass fibers [43]. The reason is probably related to the assessment of $E_{a}$ within a shear thinning regime. Our results have shown that increasing fiber concentration in composites leads to a higher activation energy. We believe that fibers prevent polymer chains to move as they would do without them. The increase of fiber concentration also leads to more interactions among fibers (friction, overlapping, etc.) and between fibers and matrix. An additional energy for flowing is then needed. A quantitative interpretation of fiber content-activation energy dependence of composites requires a separate study.

\section{DISCUSSION}

All results presented above demonstrate that composites with Tencel ${ }^{\circledR}$ fibers show higher viscosity, elasticity, apparent yield stress, and activation energy as compared to flaxbased composites at the same fiber concentration. Several reasons can be given to explain this finding. One is related to 

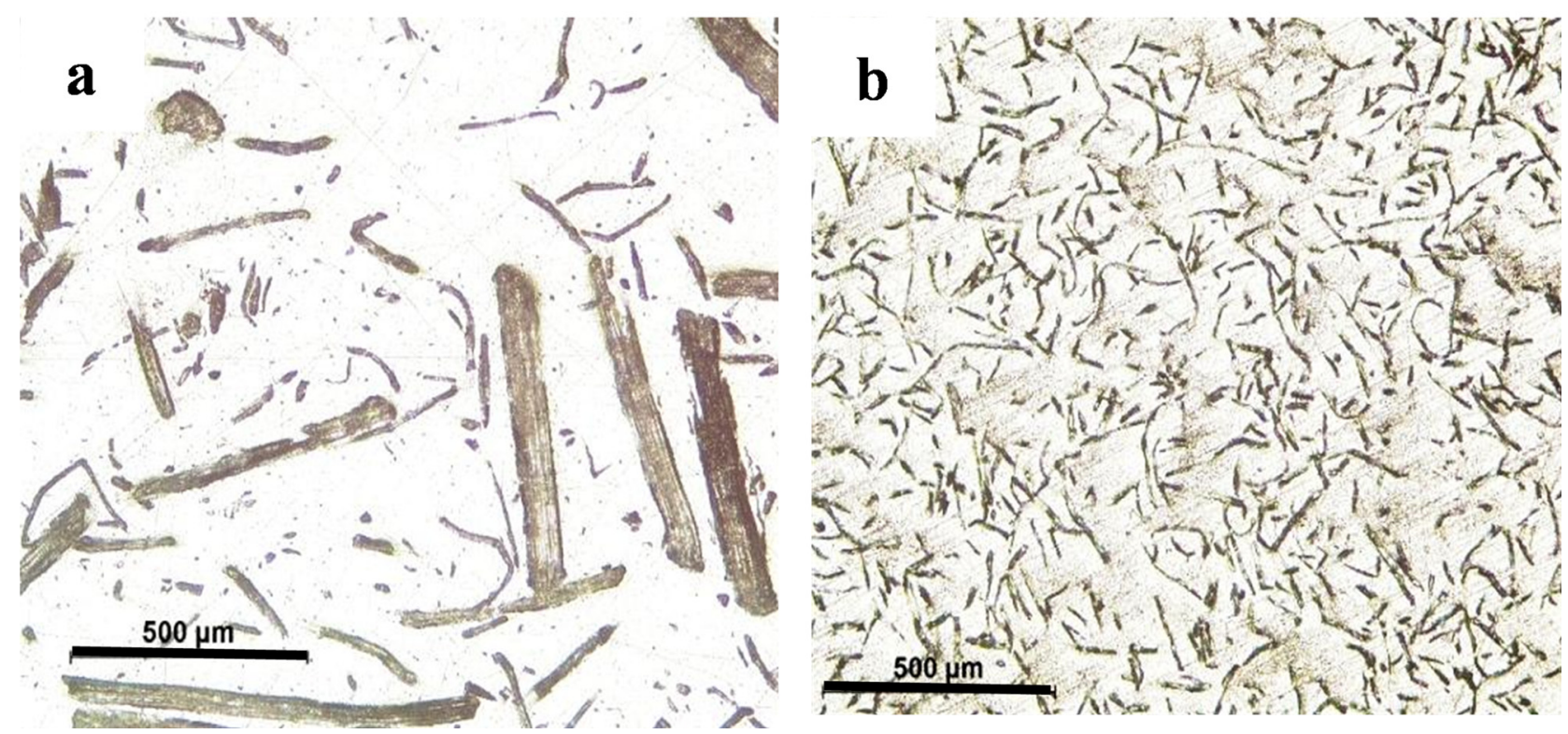

FIG. 11. Optical microscopy images of polished surfaces at the distance $100 \mu \mathrm{m}$ from the surface of the injected disk for $20 \mathrm{wt}$. \% flax (a) and Tencel ${ }^{\circledR}$ (b) composites. The bar scale represents $500 \mu \mathrm{m}$.

the number of fibers per unit volume: at the same fiber content, the number of Tencel ${ }^{\circledR}$ fibers is higher than that of flax, as far as flax diameter is at least three to ten times larger than that of Tencel ${ }^{\circledR}$ [see Fig. 2(b) for flax, Tencel ${ }^{\circledR}$ diameter is $10-11 \mu \mathrm{m}]$. After compounding, a part of flax was dissociated into elementary fibers (diameter around $10-15 \mu \mathrm{m}$ ), but another part remained in bundles with the elementary fibers glued together by lignin and pectin. Figure 11 shows pictures of polished surfaces at the depth of $100 \mu \mathrm{m}$ parallel to rheology disk surface. The number of Tencel ${ }^{\circledR}$ fibers is larger than that of flax fibers. Table II shows the number of fibers $N_{i}$ per $1 \mathrm{~mm}^{3}$ for the studied flax and Tencel ${ }^{\circledR}$ composites, calculated as follows:

$$
N_{i}=\frac{4 \phi}{\pi L_{i} D_{i}^{2}},
$$

TABLE II. Number of fibers in composite per $1 \mathrm{~mm}^{3}$ calculated with Eq. (4).

\begin{tabular}{|c|c|c|c|}
\hline Fiber concentration & Fiber type & $N_{n}$ & $N_{w}$ \\
\hline \multirow[t]{2}{*}{5 wt. $\% / 3.6$ vol. $\%$} & Flax & $\begin{array}{c}8.65 \times 10^{1} \\
(L=433, D=35)\end{array}$ & $\begin{array}{c}4.53 \times 10^{1} \\
(L=478, D=46)\end{array}$ \\
\hline & Tencel $^{\circledR}$ & $\begin{array}{c}1.91 \times 10^{3} \\
(L=240, D=10)\end{array}$ & $\begin{array}{c}1.56 \times 10^{3} \\
(L=295, D=10)\end{array}$ \\
\hline \multirow[t]{2}{*}{10 wt. $\% / 6.3$ vol. $\%$} & Flax & $\begin{array}{c}1.67 \times 10^{2} \\
(L=415, D=34)\end{array}$ & $\begin{array}{c}7.08 \times 10^{1} \\
(L=472, D=49)\end{array}$ \\
\hline & Tencel $^{\circledR}$ & $\begin{array}{c}3.32 \times 10^{3} \\
(L=242, D=10)\end{array}$ & $\begin{array}{c}2.52 \times 10^{3} \\
(L=318, D=10)\end{array}$ \\
\hline \multirow[t]{2}{*}{20 wt. $\% / 13.1$ vol. $\%$} & Flax & $\begin{array}{c}2.53 \times 10^{2} \\
(L=434, D=39)\end{array}$ & $\begin{array}{c}9.88 \times 10^{1} \\
(L=469, D=60)\end{array}$ \\
\hline & Tencel $^{\circledR}$ & $\begin{array}{c}7.04 \times 10^{3} \\
(L=237, D=10)\end{array}$ & $\begin{array}{c}5.45 \times 10^{3} \\
(L=306, D=10)\end{array}$ \\
\hline \multirow[t]{2}{*}{30 wt. $\% / 20.5$ vol. $\%$} & Flax & $\begin{array}{c}4.07 \times 10^{2} \\
(L=422, D=39)\end{array}$ & $\begin{array}{c}1.88 \times 10^{2} \\
(L=477, D=54)\end{array}$ \\
\hline & Tencel $^{\circledR}$ & $\begin{array}{c}1.34 \times 10^{4} \\
(L=195, D=10)\end{array}$ & $\begin{array}{c}9.89 \times 10^{3} \\
(L=264, D=10)\end{array}$ \\
\hline
\end{tabular}

where subscript " $i$ " is " $n$ " or " $w$ " corresponding to length and diameter weighted either in number or in weight, respectively. Based on the average length and diameters (which is a simplification of the real distribution), the number of Tencel $^{\circledR}$ fibers is found to be from 20 to 50 times larger than that of flax. The analysis of the distribution of both fiber length and diameter in natural fiber-based composite is thus a key point for the understanding of composite rheological properties and, as a consequence, for predicting composite behavior during injection.

Another reason is that the transition between the semidilute and concentrated regimes occurs at lower concentration for Tencel ${ }^{\circledR}$ fibers as compared to flax, as far as $(L / D)_{\text {Tencel }}$ is higher than $(L / D)_{\text {flax }}$ at all studied composite concentrations. For Tencel ${ }^{\circledR}$-based composites, this transition is from 3 to 5 vol. \% depending on the way $L / D$ is calculated (average in weight or in number), and for flax-based composites it is around 6-7 vol. \% (Table I). High dispersion in fiber dimensions (Figs. 1-3) and wide $L / D$ distribution do not allow the calculation of an exact value of the transition concentration. Both factors, the number of fibers per unit volume and the transition concentration, can be at the origin of a more developed network made by Tencel $^{\circledR}$, which induces higher viscosity, elasticity and apparent yield stress.

Finally, the fiber flexibility is an important reason to reveal why Tencel ${ }^{\circledR}$-based composites show a higher viscosity as compared to flax based, as discussed in the Introduction [21], see Eq. (1). We calculated fiber intrinsic flexibility $F^{*}=64$ / $\pi(L / D)^{4} 1 / E$, excluding the influence of the shear stress and fiber concentration. We used both aspect ratios, $(L / D)_{n}$ and $(L / D)_{w}$, to give the range of intrinsic flexibility values that we call $F_{n}{ }^{*}$ and $F_{w}{ }^{*}$, respectively. The results are presented in Table III. Because it is impossible to prepare flax and Tencel $^{\circledR}$-based composites with the same fiber aspect ratio using the same processing conditions, the intrinsic flexibility $F^{*}$ reflects the influence of both fiber aspect ratio and 
TABLE III. Flexibility characteristics of Tencel ${ }^{\circledR}$ and flax fibers. The aspect ratios are taken from Table I.

\begin{tabular}{lccccc}
\hline \hline & & & \multicolumn{2}{c}{ Intrinsic flexibility $F^{*}$} \\
\cline { 4 - 5 } & $E(\mathrm{GPa})$ & $(L / D)_{n}$ & $(L / D)_{w}$ & $F_{n}{ }^{*}$ & $F_{w}{ }^{*}$ \\
Flax $_{\text {Tencel }}{ }^{\circledR}$ & $30-110$ & $14-16$ & $17-20$ & $7.1 \times 10^{-6}-4.5 \times 10^{-5}$ & $1.6 \times 10^{-5}-1.1 \times 10^{-4}$ \\
\hline \hline
\end{tabular}

Young's modulus. Tencel ${ }^{\circledR}$ fibers are at least one order of magnitude more flexible than flax fibers because of higher aspect ratio and lower elastic modulus (Table III). As discussed in the Introduction, the composites containing more flexible fibers possess a higher viscosity due to the enhancement of fiber-fiber interactions. Higher apparent yield stress, viscosity, and elasticity of Tencel ${ }^{\circledR}$-based composites as compared to flax composites is hence in line with the finding of Keshtkar et al. [21] related to the influence of fiber flexibility.

\section{CONCLUSIONS}

Viscoelastic properties in the linear regime of Tencel ${ }^{\circledR}$ and flax PP molten composites were studied using oscillatory rheology. Fiber concentration was varied from 5 to $30 \mathrm{wt}$. \% (corresponding to 3.6-20.5 vol. \%, respectively), and composite temperature was from 180 to $200^{\circ} \mathrm{C}$. Tencel ${ }^{\circledR}$ is a man-made $100 \%$ cellulose-based flexible fiber with a uniform diameter (around $10 \mu \mathrm{m}$ ), while flax is a mixture of semirigid elementary fibers and rigid bundles made of several elementary fibers assembled together. The analysis of fiber dimensions in composites showed that fibers were broken during compounding. Tencel ${ }^{\circledR}$ aspect ratio is higher than that of flax over all studied concentrations. The majority of flax remained as nondissociated bundles with diameter varying from 20 to $80 \mu \mathrm{m}$.

The activation energy was calculated from viscositytemperature dependence for all studied concentrations. When fiber content increases, the activation energy becomes larger, which is interpreted by the supplementary energy needed to flow a composite compared to the neat polymer matrix.

The increase in fiber concentration led to greater viscosity, elastic and viscous moduli, and apparent yield stress. The apparent yield stress was explained by the formation of fiber network structure above the percolation concentration. At a given fiber concentration dynamic viscosity, elastic, and viscous moduli, apparent yield stress and activation energy were higher for Tencel ${ }^{\circledR}$-based composites as compared to flax-based ones. Several reasons are behind this phenomenon. One is that the number of Tencel ${ }^{\circledR}$ fibers in the composite is higher as compared to flax fibers which remained mostly in bundles after compounding. Tencel ${ }^{\circledR}$-based composites are far more elastic than flax based ones because their fiber aspect ratio is greater. Finally, a parameter quantifying fiber flexibility was applied to the studied composites. It was demonstrated that Tencel ${ }^{\circledR}$ fibers, having higher aspect ratio and lower elastic modulus compared to flax, are more flexible than flax. For the same given fiber concentration, higher flexibility and larger number of fibers would result in a larger number of fiber-fiber interactions. This, in turn, leads to higher composite viscosity, apparent yield stress, and activation energy.

\section{ACKNOWLEDGMENTS}

This study has been carried out in the frame of the "Bioplastics" Industrial Chair supported by Mines ParisTech, Arkema, L'Oréal, Nestlé, PSA, and Schneider Electric. The authors are grateful to Lenzing, Austria, for providing Tencel ${ }^{\circledR}$ fibers and Benjamin Gallard (Ecole des Mines d'Ales, France) for the help in extrusion experiments.

\section{References}

[1] Shah, D. U., P. J. Schubel, and M. J. Clifford, "Can flax replace Eglass in structural composites? A small wind turbine blade case study," Composites: Part B 52, 172-181 (2013).

[2] Basu, D., A. N. Banerjee, and A. Misra, "Comparative rheological studies on jute-fiber- and glass-fiber-filled polypropylene composite melts,” J. Appl. Polym. Sci. 46, 1999-2009 (1992).

[3] Barnes, H. A., "A review of the rheology of filled viscoelastic systems," Rheol. Rev. 2003, 1-36.

[4] Mohanty, S., S. K. Verma, and S. K. Nayak, "Rheological characterization of PP/jute composite melts," J. Appl. Polym. Sci. 99, 1476-1484 (2006).

[5] Azizi, H., and I. Ghasemi, "Investigation on the dynamic melt rheological properties of polypropylene/wood flour composites," Polym. Compos. 30, 429-435 (2009).

[6] Twite-Kabamba, E., A. Mechraoui, and D. Rodrigue, "Rheological properties of polypropylene/hemp fiber composites," Polym. Compos. 30, 1401-1407 (2009).

[7] Le Moigne, N., M. Van den Oever, and T. Budtova, "Dynamic and capillary shear rheology of natural fiber-reinforced composites," Polym. Eng. Sci. 53, 2582-2593 (2013).

[8] Sojoudiasli, H., M-C. Heuzey, and P. J. Carreau, "Rheological, morphological and mechanical properties of flax fiber polypropylene composites: Influence of compatibilizers," Cellulose 21, 3797-3812 (2014).

[9] Greene, J. P., "Steady-state and dynamic properties of concentrated fiber-filled thermoplastics," Polym. Eng. Sci. 35, 1670-1681 (1995).

[10] Thomasset, J., P. J. Carreau, B. Sanschagrin, and G. Ausias, "Rheological properties of long glass fiber filled polypropylene," J Non-Newtonian Fluid Mechanics 125, 25-34 (2005).

[11] Eberle, A. P. R., D. G. Baird, and P. Wapperom, "Rheology of nonNewtonian fluids containing glass fibers: A review of experimental literature,” Ind. Eng. Chem. Res. 47, 3470-3488 (2008).

[12] Hristov, V., and J. Vlachopoulos, "Influence of coupling agents on melt flow behavior of natural fiber composites," Macromol. Mater. Eng. 292, 608-619 (2007).

[13] Le Moigne, N., M. V. D. Oever, and T. Budtova, "A statistical analysis of fibre size and shape distribution after compounding in composites 
reinforced by natural fibres," Composites: Part A 42, 1542-1550 (2011).

[14] Le Duc, A., B. Vergnes, and T. Budtova, "Polypropylene/natural fibres composites: Analysis of fibre dimensions after compounding and observations of fibre rupture by rheo-optics," Composites: Part A 42, 1727-1737 (2011).

[15] Charlet, K., J. P. Jernot, S. Eve, M. Gomina, and J. Bréard, "Multiscale morphological characterisation of flax: From the stem to the fibrils," Carbohydr. Polym. 82, 54-61 (2010).

[16] Charlet, K., J. P. Jernot, J. Bréard, and M. Gomina, "Scattering of morphological properties of flax fibres," Ind. Crops Prod. 32, 220-224 (2010).

[17] Gassan, J., "Calculation of elastic properties of natural fibers," J. Mater. Sci. 36, 3715-3720 (2001).

[18] Baley, C., "Analysis of the flax fibres tensile behaviour and analysis of the tensile stiffness increase," Composites: Part A 33, 939-948 (2002).

[19] Charlet, K., J. P. Jernot, S. Eve, M. Gomina, and J. Bréard, "Tensile deformation of flax fiber," Procedia Eng. 1, 233-236 (2009).

[20] Switzer, L. H., and D. J. Klingenberg, "Rheology of sheared flexible fiber suspensions via fiber-level simulations," J. Rheol. 47, 759-778 (2003).

[21] Keshtkar, M., M. C. Heuzey, and P. J. Carreau, "Rheological behaviour of filled model suspensions: Effect of fibre flexibility," J. Rheol. 53, 631-650 (2009).

[22] Kerekes, R. J., R. M. Soszynski, and P. A. Tam Doo, "The flocculation of pulp fibres, papermaking raw materials," in Transactions of the Eighth Fundamental Research Symposium held at Oxford, edited by V. Punton, (Mechanical Engineering Publications, Ltd., London, 1985), pp. 265-310.

[23] Bennington, C. P. J., R. J. Kerekes, and J. R. Grace, “The yield stress of fibre suspensions," Can. J. Chem. Eng. 68, 748-756 (1990).

[24] Bos, L. H., J. Müssig, and M. J. A. Van den Oever, "Mechanical properties of short-flax-fibre reinforced compounds," Composites: Part A 37, 1591-1604 (2006).

[25] Ganster, J., and H.-P. Fink, "Novel cellulose reinforced thermoplastic," Cellulose 13, 271-280 (2006).

[26] Hornsby, P. R., E. Hinrichsen, and K. Tarverdi, "Preparation and properties of polypropylene composites reinforced with wheat flax straw fibres, Part II: Analysis of composites microstructure and mechanical properties," J. Mater. Sci. 32, 1009-1015 (1997).

[27] Franzèn, B., C. Klason, J. Kubat, and T. Kitano, "Fibre degradation during processing of short fibre reinforced thermpolastics," Composites 20, 65-75 (1989).

[28] Akay, M., and D. Barkley, "Fibre orientation and mechanical behaviour in reinforced thermoplastic injection mouldings," J. Mater. Sci. 26, 2731-2742 (1991).

[29] Fu, S.-Y., X. Hu, and C.-Y. Yue, "Effects of fiber length and orientation distributions on the mechanical properties of short-fiber-reinforced-polymers," Mater. Sci. Res. Int. 5, 74-83 (1999).
[30] Yilmazer, U., and M. Cansever, "Effects of processing conditions on the fiber length distribution and mechanical properties of glass fiber reinforced Nylon-6," Polym. Compos. 23, 61-71 (2002).

[31] See supplementary material at http://dx.doi.org/10.1122/1.4938224 for 1) example of fiber orientation in the disk; 2) viscosity of composites without pre-shear with different gaps; 3) example of reproducibility of viscosity-frequency dependence; 4) influence of pre-shear on the viscosity of composites; 5) elastic and viscous moduli of composites as a function of time and 6) complex viscosity vs shear stress for flax/PP composite.

[32] Kitano, T., T. Kataoka, and Y. Nagatsuka, "Shear flow rheological properties of vinylon- and glass-fiber reinforced polyethylene melts," Rheol. Acta 23, 20-30 (1984).

[33] Drozdov, A. D., A. Al-Mulla, and R. K. Gupta, "The viscoelastic and viscoplastic behavior of polymer composites: Polycarbonate reinforced with short glass fibers," Comput. Matet. Sci. 28, 16-30 (2003).

[34] Mobuchon, C., P. J. Carreau, M. C. Heuzey, M. Sepehr, and G. Ausias, "Shear and exentensional properties of short glass fiber reinforced polypropylene," Polym. Compos. 26, 247-264 (2005).

[35] Guo, R., J. Azaiez, and C. Bellehumeur, "Rheology of fiber filled polymer melts role of fiber-fiber interactions and polymer-fiber coupling," Polym. Eng. Sci. 45, 385-399 (2005).

[36] Cheng, D. C.-H., "Yield stress: A time-dependent property and how to measure it," Rheol. Acta 25, 542-554 (1986)

[37] Barnes, H. A., "The yield stress—a review or ' $\pi \alpha \nu \tau \alpha \rho o l$ '—everything flows?” J. Non-Newtonian Fluid Mech. 81, 133-178 (1999).

[38] Ghanbari, A., M.-C. Heuzey, P. J. Carreau, and M.-T. Ton-That, "Morphological and rheological properties of PET/clay nanocomposites," Rheol. Acta 52, 59-74 (2013).

[39] Laun, H. M., "Orientation effects and rheology of short glass fiberreinforced thermoplastics," J. Colloid Polym. Sci. 262, 257-269 (1984).

[40] De Guzmán, J., "Relación entre la Fluidez y el Calor de Fusion,” An. Soc. Esp. Fis. Quim. 11, 353-362 (1913).

[41] Eyring, H., "The activated complex in chemical reactions," J. Chem. Phys. 3, 107-115 (1935).

[42] Eyring, H., "Viscosity, plasticity, and diffusion as examples of absolute reaction rates," J. Chem. Phys. 4, 283-291 (1936).

[43] Tiptipakorn, S., S. Rimdusit, S. Damrongsakkul, and T. Kitano, "Thermomechanical and rheological behaviours of waste glass fibrefilled polypropylene composites,” Eng. J. 13, 45-59 (2009).

[44] Islam, M. A., and K. Begum, "Rheological behavior of coir-fiber-filled polypropylene composites at constant shear stress," Polym. Compos. 36, 51-61 (2015).

[45] Feng, Y., D. Zhang, J. Qu, H. He, and B. Xu, "Rheological properties of sisal fiber/poly(butylene succinate) composites," Polym. Testing 30, 124-130 (2011). 